\title{
Prognostic value of CA125 in advanced heart failure patients
}

\author{
Sílvia Monteiro ${ }^{\mathrm{a}, *}$, Fátima franco $^{\mathrm{a}}$, Susana Costa $^{\mathrm{a}}$, Pedro Monteiro ${ }^{\mathrm{a}, \mathrm{b}}$, Henrique Vieira $^{\mathrm{a}}$, \\ Lourenço Coelho $^{\mathrm{a}}$, Luís Oliveira ${ }^{\mathrm{a}}$, Luís A. Providência ${ }^{\mathrm{a}, \mathrm{b}}$ \\ ${ }^{a}$ Cardiology Department of Coimbra University Hospital, Portugal \\ ${ }^{\mathrm{b}}$ Coimbra Medical School, Portugal
}

Received 27 April 2008; received in revised form 17 August 2008; accepted 1 November 2008

\begin{abstract}
Introduction: Serum levels of CA125 are often high in advanced heart failure (AHF) patients.

Aim: To determine the predictive value of CA125 in forecasting the occurrence of death or cardiac transplantation in an AHF population. Methods: 88 AHF patients referred for heart transplantation were divided into 2 groups based on CA125 levels: normal (CA125<38 U/mL) and elevated $(\geq 38 \mathrm{U} / \mathrm{mL})$. Events (death or heart transplant) were monitored over a period of $13 \pm 7$ months after CA125 determination. Results: Patients with elevated CA125 $(n=65)$ had significantly lower blood pressure, body mass index, serum sodium and peak exercise oxygen consumption, while B-type natriuretic peptide levels were significantly higher. The combined primary endpoint (death or heart transplant) rate was $39.4 \%$ and $62.3 \%$ in normal and elevated CA125 groups, respectively $(p=0.029)$. Multivariate regression analysis showed that CA125 and sodium levels were the only independent predictors of the combined endpoint.

Conclusion: In AHF patients, plasma CA125 was an effective prognostic marker. Its determination may contribute to better risk stratification in this population.
\end{abstract}

(C) 2008 Elsevier Ireland Ltd. All rights reserved.

Keywords: CA125; Advanced heart failure; Cardiac transplantation; Prognostic marker

\section{Introduction}

Advanced heart failure (AHF) is associated with high morbidity and mortality rates [1-3], unless cardiac transplantation is performed. Risk stratification of AHF patients is a critical component of the transplant candidate selection process; therefore, search for new prognostic markers in AHF has recently been intensified.

Carbohydrate antigen 125 (CA125) is a tumour marker classically associated with ovarian cancer [4]; recently several studies reported increased serum CA125 levels in HF patients [5-15].

\footnotetext{
* Corresponding author. Tel.: +351966556027 ; fax: +351239084893 .

E-mail address: silvia.reis.monteiro@gmail.com (S. Monteiro).
}

Table 1

Clinical characteristics of the study population of advanced heart failure patients $(n=88)$

\begin{tabular}{ll}
\hline Age (years) & $53.5 \pm 13.8$ \\
Men/women & $62(70 \%) / 26(30 \%)$ \\
Body mass index $\left(\mathrm{kg} / \mathrm{m}^{2}\right)$ & $24.0 \pm 5.0$ \\
LVEF (\%) & $24.5 \pm 11.2$ \\
NYHA functional class (\%) & \\
III & 58.1 \\
IV & 41.9 \\
Aetiology (\%) & 49 \\
$\quad$ Dilated cardiomyopathy & 40 \\
Coronary artery disease & 10 \\
Hypertensive heart disease & 1 \\
Other &
\end{tabular}

Data are presented as the mean value $\pm \mathrm{SD}$, number or percentage of patients. LVEF - left ventricular ejection fraction; NYHA - New York Heart Association. 
Table 2

Clinical, laboratory and echocardiographic parameters of advanced heart failure patients, classified according to CA125 levels

\begin{tabular}{lccc}
\hline & CA125 $<38 \mathrm{U} / \mathrm{mL}$ & CA125 $\geq 38 \mathrm{U} / \mathrm{mL}$ & $p$ \\
\hline Heart rate $(\mathrm{bpm})$ & $73.8 \pm 11.5$ & $83.1 \pm 15.3$ & 0.015 \\
SBP $(\mathrm{mmHg})$ & $109.8 \pm 17.7$ & $97.0 \pm 14.6$ & 0.006 \\
DBP $(\mathrm{mmHg})$ & $66.1 \pm 13.8$ & $56.7 \pm 10.3$ & 0.01 \\
Body mass index $\left(\mathrm{kg} / \mathrm{m}^{2}\right)$ & $24.8 \pm 6.5$ & $23.4 \pm 3.2$ & 0.04 \\
Serum Sodium $(\mathrm{mmol} / \mathrm{L})$ & $135.9 \pm 4.5$ & $133.9 \pm 4.1$ & 0.04 \\
Serum creatinine $(\mathrm{mg} / \mathrm{dL})$ & $1.4 \pm 0.5$ & $1.7 \pm 1.7$ & 0.80 \\
BNP $(\mathrm{pg} / \mathrm{mL})$ & $593.4 \pm 554.9$ & $2180.1 \pm 1468.7$ & $<0.001$ \\
LVEF $(\%)$ & $24.7 \pm 11.5$ & $24.3 \pm 11.1$ & 0.92 \\
Peak $\mathrm{VO}_{2}(\mathrm{~mL} / \mathrm{kg} / \mathrm{min})$ & $16.0 \pm 5.1$ & $13.8 \pm 3.4$ & 0.049 \\
\hline
\end{tabular}

SBP — systolic blood pressure; DBP — diastolic blood pressure; BNP - B type natriuretic peptide; LVEF - left ventricular ejection fraction; Peak $\mathrm{VO}_{2}$ - peak exercise oxygen consumption.

However, it is still a matter of debate if CA125 is a potential prognostic marker for AHF and also if it is useful for evaluating and managing pre-transplant patients.

The aim of the present study was to determine the predictive value of plasma CA125 in forecasting the occurrence of death or cardiac transplantation in an AHF patient population.

\subsection{Patients and methods}

This study included 88 consecutive AHF patients referred for heart transplantation (62 male, mean age 53.5 \pm 13.8 years) - Table 1 .

CA125 assays were performed during clinic visits or during hospitalization for HF, after clinical stabilization ( $7 \pm 3$ days). Serum levels of CA1 25 were measured by chemiluminescence (BRAHMS CA125 II KRYPTOR), with an upper normal limit of $38 \mathrm{U} / \mathrm{mL}$. Population was divided into two groups according to CA125 levels: normal (CA125 $<38 \mathrm{U} / \mathrm{mL})$ and elevated $(\geq 38 \mathrm{U} / \mathrm{mL})$.

Patients were followed for a mean period of $13 \pm 7$ months after CA125 assessment; the study primary endpoint was death or heart transplant.

\subsection{Statistical analysis}

Data are presented as the mean value $\pm \mathrm{SD}$. Analysis of groups differences was performed using the Mann-Whitney $U$ test for continuous variables and $\chi^{2}$ test for categorical variables. A $p$ value $<0.05$ was considered statistically significant. Survival curves were constructed by the KaplanMeier method and were compared using the log-rank test. Multivariate regression analysis was then performed to determine the independent predictors of the primary endpoint.

\section{Results}

Twenty-three patients had normal CA125 $(15.3 \pm 6.1 \mathrm{U} / \mathrm{mL})$, while 65 had elevated levels $(215.6 \pm 260.2 \mathrm{U} / \mathrm{mL})$. Groups were similar regarding demographic characteristics, HF aetiology and medication.

Compared to the normal group, patients with elevated CA125 had significantly lower systolic and diastolic blood pressure, body mass index, serum sodium and peak oxygen consumption in the cardio-respiratory stress test. B-type natriuretic peptide (BNP) levels were also significantly higher in this group (Table 2).

In elevated CA125 group, 38\% of patients had pleural effusion versus none in normal CA125 group $(p=0.014)$.

\section{Event-free survival curve: Heart transplant and death}

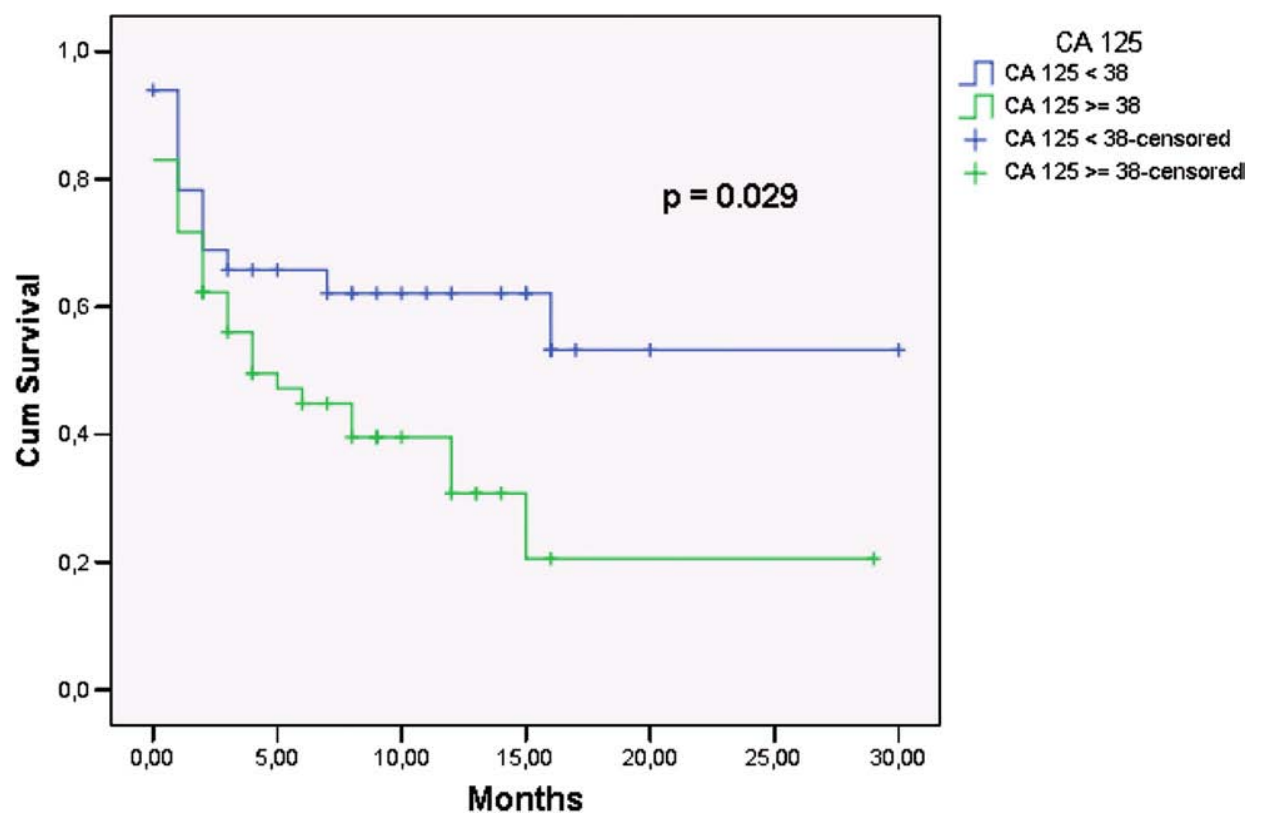

Fig. 1. Kaplan-Meier cumulative event-free survival curves separated according to CA125 levels. 
Table 3

Multiple regression analysis

\begin{tabular}{llll}
\hline Variables & Beta & $p$-value & OR \\
\hline $\mathrm{CA} 125 \geq 38 \mathrm{U} / \mathrm{mL}$ & 1.152 & 0.032 & $3.163(1.107-9.036)$ \\
$\mathrm{NA} \leq 132.5 \mathrm{mmol} / \mathrm{L}$ & 1.339 & 0.041 & $3.817(1.056-13.799)$ \\
\hline
\end{tabular}

c-statistic 0.728

Event rate was significantly lower in patients with normal CA125 levels: 2 versus 15 died, 11 versus 19 were transplanted and 13 versus 27 were readmitted for worsening HF. The combined primary endpoint (death or heart transplant) rate was $39.4 \%$ in patients with normal CA125 values and $62.3 \%$ in the elevated CA125 group $(p=0.029)$ - Fig. 1.

Multivariate regression analysis showed that CA125 and sodium levels were the only independent predictors of the combined endpoint (Table 3).

\section{Discussion}

Numerous studies showed increased CA125 levels in CHF patients and a relationship between these values and HF severity [5-15]. In the present study, we investigated the prognostic value of CA125 levels in an AHF population.

According to our results, serum CA125 was elevated in most AHF patients and its levels were significantly related to blood pressure, body mass index, serum sodium, peak exercise oxygen consumption and BNP levels (established markers of severity and prognosis in HF).

We did not find significant differences in LVEF between patients with normal and elevated CA125, probably because our population included mainly severe AHF patients with low LVEF $(24.5 \pm 11.2 \%)$ and LVEF is not a good marker to stratify AHF patients [1].

Our data clearly demonstrated that CA125 is a marker of adverse outcome in AHF patients, associated with increased mortality, transplant and hospital readmission rates. Multivariate analysis identified CA125 as an independent predictor for the combined endpoint death or heart transplant.

In several reports high CA125 was associated with serosal effusions, suggesting that the presence of serosal fluids may stimulate its release [8-10].

However, other investigators showed increased CA125 levels in HF patients without serosal effusion, indicating that an acute congestion may not be the sole cause of CA125 secretion $[6,7]$.

The majority of our patients with high CA125 did not have pleural effusion, either because they were clinically stable or because many AHF patients do not have serosal effusions.

Recently, Kosar [16] demonstrated that high CA125 levels in HF patients were correlated with inflammatory cytokines levels, suggesting a relationship between CA125 and cytokines.

As in our study CA125 was measured during routine clinic visits or in hospitalized patients (but after clinical stabilization), our results support the hypothesis that CA125 is an effective marker of AHF severity and prognosis, even in compensated phases of the disease.

\section{Conclusion}

In AHF patients, CA125 is an independent predictor of worse prognosis, associated with a higher event rate and increased mortality. Even in stable patients CA125 is a useful marker of AHF severity and prognosis, which can be used to improve risk stratification and guide therapeutic decisions.

\section{Acknowledgement}

The authors of this manuscript have certified that they comply with the Principles of Ethical Publishing in the International Journal of Cardiology [17].

\section{References}

[1] The task force for the diagnosis and treatment of chronic heart failure of the European society of cardiology. Guidelines for the diagnosis and treatment of chronic heart failure: executive summary (update 2005). Eur Heart J 2005;26:1115-40.

[2] Hunt SA, Abraham WT, Chin MH, et al. ACC/AHA 2005 guideline update for the diagnosis and management of chronic heart failure in the adult. Circulation 2005;112:154-235.

[3] Mosterd A, Hoes AW, de Bruyne MC, et al. Prevalence of heart failure and left ventricular dysfunction in the general population. Eur Heart $\mathrm{J}$ 1999;20:447-55.

[4] Bast RC, Badgwell D, Lu Z, et al. New tumour markers: CA125 and beyond. Int J Gynecol Cancer 2005;15:274-81.

[5] Nagele H, Bahlo M, Klapdor R, Schaeperkoetter D, Rodiger W. CA125 and its relation to cardiac function. Am Heart J 1999;137:1044-9.

[6] D'Aloia A, Faggiano P, Aurigemma G, et al. Serum levels of carbohydrate antigen 125 in patients with chronic heart failure. Relation to clinical severity hemodynamic and doppler echocardiographic abnormalities, and short-term prognosis. J Am Coll Cardiol 2003;41: $1805-11$

[7] Kouris NT, Zacharos ID, Kontogianni DD, et al. The significance of CA125 levels in patients with chronic congestive heart failure. Correlation with clinical and echocardiographic parameters. Eur J Heart Fail 2005;7:199-203.

[8] Varol E, Ozaydin M, Dogan A, Kosar F. Tumour marker levels in patients with chronic heart failure. Eur J Heart Fail 2005;7:840-3.

[9] Seo T, Ikeda Y, Onaka H, et al. Usefulness of serum CA125 measurement for monitoring pericardial effusion. Jpn Circ J 1993;57:489-94.

[10] Turk HM, Pekdemir H, Buyukberber S, et al. Serum CA125 levels in patients with chronic heart failure and accompanying pleural fluid. Tumour Biol 2003;24:172-5.

[11] Duman C, Ercan E, Tengiz I, Bozdemir H, Ercan HE, Nalbantgil I. Elevated serum CA125 levels in mitral stenotic patients with heart failure. Cardiology 2003;100:7-10.

[12] Skorzynska H, Solski J, Gernand W, Matras P, Gniwek M, Sokol M. Estimation of CA125 concentration in patients with congestive heart failure. Ann Univ Mariae Curie Sklodowska[Med] 2004;59:261-4.

[13] Sugishita H, Imagawa H, Kawachi K, Takano S, Tsunooka N, Shikata F. Normalization of cancer antigen 125 after mitral valve replacement in a patient with congestive heart failure due to mitral valve endocarditis. Jpn J Thorac Cardiovasc Surg 2005;53:486-9.

[14] Kouris NT, Kontogianni DD, Papoulia EP, et al. Clinical and prognostic value of elevated CA125 levels in patients with 
congestive heart failure. Hellenic J Cardiol (Greece) 2006;47(5): 269-742.

[15] Antonini-Canterin F, Popescu BA, Popescu AC, et al. Heart failure in patients with aortic stenosis: clinical and prognostic significance of carbohydrate antigen 125 and brain natriuretic peptide measurement. Int J Cardiol 2008;128(3):406-12.
[16] Kosar F, Aksoy Y, Ozguntekin G, Ozerol I, Varol E. Relationship between cytokines and tumour markers in patients with chronic heart failure. Eur J Heart Fail 2006;8:270-4.

[17] Coats AJ. Ethical authorship and publishing. Int J Cardiol 2009;131: $149-50$. 